\title{
Study of Mixed Polycyclic Aromatic Hydrocarbon Degradation by Bacteria Isolated From Hydrocarbon Contaminated Sites
}

\author{
Vivek Parab ${ }^{1}$, Manju Phadke ${ }^{2}$ \\ ${ }^{1,2}$ Department of Microbiology, SIES College of Arts, Science and Commerce, Sion (West), Mumbai, University of Mumbai.
}

\begin{abstract}
Polycyclic aromatic hydrocarbons $(P A H S)$ are considered to be environmental pollutants toxic to human health system. Phenanthrene and naphthalene are the commonly found PAHs in the environment which in large amounts are carcinogenic and hence potentially harmful.In the present study, soil samples obtained from niche areas rich in petroleum waste were used to isolate PAH degrading microorganisms. Using the preliminary screening process, 8 isolates out of a total of 25 isolates were selected, out of which 6 showed a high rate of degradation of phenanthrene and naphthalene. Growth curve experiments were performed on the selected isolates using phenanthrene and naphthalene as a stressor. The present study has revealed that PAH degraders are mostly Gram negative short rods and Gram positive rods, with a good rate of PAH degradation. The studies on the growth curve have revealed that organisms could resist a total concentration from $10 \mathrm{mg} / \mathrm{L}$ to $500 \mathrm{mg} / \mathrm{L}$ of phenanthrene and naphthalene each and they could grow without stress. The study also focussed on determining the concentration of PAH present in the area of study which was Sewri, Mumbai. GC-MS studies carried out on water samples revealed that a total concentration of $P A H$ was ranging from $1.47 \times 10^{2}-6.52 \times 10^{2} \mathrm{mg} / \mathrm{L}$ which was more than the permissible limits set by WHO for PAH in water bodies which is $0.1 \times 10^{-6}-1.3 \times 10^{-6} \mathrm{mg} / \mathrm{L}$.
\end{abstract}

Keywords - Polycyclic aromatic hydrocarbon degraders, Phenanthrene, Naphthalene, Environment pollutants, PAH analysis, Bacterial PAH degradation.

\section{Introduction}

Polycyclic aromatic hydrocarbons (PAHs) are contaminants that are widespread in environment which are of great concern. These are major components of fossil fuel, formed during the incomplete combustion of fossil fuels, coal, gas and oil, domestic garbage, tobacco smoke, soot etc. $[18,20]$. Thus, PAHs are commonly detected in air, soil, and water. Therefore, PAHs are considered ubiquitous in the environment.There is an increased accumulation of polycyclic aromatic hydrocarbons (PAHs) in multiple environments like urban soils contaminated with different hydrocarbons, garage soil and bunk soil of petrol pump. Along with territorial regions, hydrocarbon contamination can also be observed in coastal regions, suchpolluted coastal regions result in a notable damage to the marine ecosystems. PAHs are listed among the US EPA and the EU priority pollutants list. They have also been listed as pollutants by MPCB [11]. PAHs are deposited in surface waters and sediment from atmosphere, urban run-off, domestic, municipal and industrial effluents, and oil leakage or spillage [3].

PAHs have a low water solubility and strong hydrophobic nature hence they are hardly soluble in water but are well soluble in fats,they tend to accumulate and associate with the sediments and particulate materials in the aquatic environment. This results in PAHs getting accumulated in food chains, due to their high hydrophobicity for fatty tissues. If these contaminants get accumulated in fishes, after consumption they enter human body which can further lead to health hazards.PAHs are proved to becarcinogenic in naturehaving mutagenic effects and are potent immunosuppressants. The mechanism of toxicity is that they interfere with the function of cellular membranes as well as with the enzyme systems associated with the membrane.Detrimental effects have been documented on immune system development, humoralimmunity and on host resistance [6].Thus,suggesting that the contamination of PAHs is a large threat to the safety of human health if consumed by any means. There are many studies conducted for the removal of PAHs from contamination sites. Bioremediation is an ideal, cost-effective method of removing PAH from the contaminated environment. Microbial degradation is considered as one of the main applications for PAH remediation in the environment [2, 7]. Bacteria with high capacities for degrading PAHs have been isolated [16, 8]. Polycyclic aromatic hydrocarbons may undergo adsorption, volatilization, photolysis, and chemical degradation, but microbial degradation appears to be the process majorly responsible for the removal of PAHs in a soil system[14]. Hence, bioremediation is regarded as an alternative method to detoxify or remove PAHs from the environment. Naphthalene and phenanthrene arethe most abundantly found Low-molecular weight PAHs found in environment [2,7].Naphthalene and phenanthrene are often used as a model substance for microbial metabolism of PAHs. Recent studies have shown that naphthalene and phenanthrene can be degraded by different bacteria such as species of Pseudomonas, Sphingomonas, Rhodococcus, Xanthomonas and Mycobacterium. [13, 12].

In biodegradation of low molecular weight PAHs like naphthalene and phenanthrene, dihydroxylated aromatics and catechol are subjected to aromatic ring fission by intradiol- or extradiol-type dioxygenases. The mechanism of ringcleavage involves the enzyme intradiol type dioxygenase cleaving the aromatic ring between two hydroxylated carbons, while extradiol-type dioxygenases opening the aromatic ring by cleavage between the hydroxylated carbon and adjacent non-hydroxylated carbon. Two key enzymes involved during PAH biodegradation are PAH dioxygenase (PDO) and catechol 2, 3-dioxygenase (C23O). Catechol and its derivatives are key metabolic intermediates in the catabolic pathway for aerobic degradation of monocyclic and polycyclic aromatic compounds. Catechol 2, 3-dioxygenase is an extradiol-type dioxygenase opening the aromatic ring of catechol and hence this enzyme plays a major role in the metabolism of aromatic hydrocarbons $[4,12]$.

The present study is aimed at isolating the PAH degrading microorganisms from soil samples highly contaminated with hydrocarbon waste and study mixed PAH degradation by the isolates. The standard PAHs used for the study were naphthalene and phenanthrene. Further studies were carried to check the growth rate in the presence of high concentration of 
mixed PAH as sole source of carbon, calculate the rate of degradationby the selected PAH degrading isolates based on catechol metabolism and Gas Chromatography (GC) analysis. The study also aims at determining the amount of PAH in water bodies from a selected area of study.

\section{Materials And Methods}

\section{Isolation and screening of PAH degrading microorganisms}

For the isolation of PAH degrading microorganisms, soil samples were collected from areas contaminated with hydrocarbon waste. The sampling areas include bunk soil from local petrol pump in Chembur, Mumbai and Dadar, Mumbai, contaminated beach sand from Kelva beach, garage soil samples from Amar Mahal and Amar Nagar, Mumbai, soil sample from Bandstand promenade, Mumbai, soil sample near Sewri, Mumbai and Mahul Toll naka, Mumbai. The soil samples were collected in an air-tight zipper pouch and refrigerated at $4^{\circ} \mathrm{C}$.

The soil samples were initially enriched using sterile Mineral Salt Medium (MSM). The enrichment was carried out by adding 2 grams of soil samples in $250 \mathrm{~mL}$ Erlenmeyer flask containing $100 \mathrm{~mL}$ sterile MSM medium containing 10 $\mathrm{mg} / \mathrm{L}$ of naphthalene and phenanthrene as sole sources of carbon. Naphthalene was purchased from LobaChemie (99\% pure) and phenanthrene was purchased from HiMedia Labs (98\% pure). The flasks were kept for incubation for 1 week at $30^{\circ} \mathrm{C}$ under shaker condition.

Isolation was carried out on sterile Mineral Salt Agar (MSA). The solutions of naphthalene and phenanthrene were prepared in $1 \mathrm{M} \mathrm{CCL}_{4}$ and were supplied on each plate by spray plate method under aseptic conditions. The plates were further incubated at $30^{\circ} \mathrm{c}$.

\section{Screening of PAH degrading bacteria}

The plates were checked for the production of catechol 2,3-dioxygenase enzyme produced during degradation of naphthalene and phenanthrene using Franklin's method. A drop of $100 \mathrm{mM}$ catechol was added on the growing colonies and the plates were kept undisturbed to observe the colour change. The colonies turning reddish brown under 1 minute was an indication of production of enzyme formed after metabolism of PAH.

\section{Determination of catechol production during PAH metabolism}

Catechol production during the metabolism of naphthalene and phenanthrene was checked using Arnow's assay by plotting a standard curve of catechol. $1 \mathrm{~mL}$ of catechol (Pyrocatechol ( $98 \% 0$ from LobaChemie) of different concentrations $(1 \mathrm{mM}-8 \mathrm{mM})$ were mixed with $1 \mathrm{~mL}$ of $0.5 \mathrm{~N} \mathrm{HCL}, 5 \mathrm{~mL}$ of Nitrite molybdate reagent and $1 \mathrm{~mL}$ of $1 \mathrm{~N} \mathrm{NaOH}$. Golden Yellow to Amber colour is produced in the mixture which is measured using a Digital Colorimeter (EQ 650 A by Equitronic) at 500nm. Quantitative determination of catechol produced by isolates during naphthalene and phenanthrene was done by inoculation of isolates in 250 ML Erlenmeyer flasks containing $100 \mathrm{~mL}$ of sterile MSM broth and incubated under shaker conditions at $30^{\circ} \mathrm{C}$. The media was supplied by $100 \mathrm{mg} / \mathrm{L}$ of PAH in each flask. The Arnow's assay was performed by preparing culture suspensions. $1 \mathrm{~mL}$ of suspension was mixed with the amount of solution same as standard and checked for golden yellow to amber colour production measured using Digital Colorimeter at 500nm.

\section{Growth response during individual and mixed PAH degradation and tolerance towards higher concentrations of PAH}

The selected isolates from preliminary screening process were inoculated in sterileMSM broth containing different concentrations ( $1 \mathrm{mg} / \mathrm{L}$ to $10 \mathrm{mg} / \mathrm{L})$ of naphthalene and phenanthrene both individually and in a form of mixture. Higher concentrations of mixture of PAH $(100 \mathrm{mg} / \mathrm{L}$ and $500 \mathrm{mg} / \mathrm{L}$ each of naphthalene and phenanthrene) as a sole carbon source were added to sterile MSM in a single $250 \mathrm{~mL}$ Erlenmeyer flask and incubated at $30^{\circ} \mathrm{C}$ under shaker condition. Growth was checked periodically at the intervals of 12 hours against un-inoculated sterile MSM as blank using Digital Colorimeter at $615 \mathrm{~nm}$.

\section{Analysis of Mixed PAH degradation using GC}

Degradation of mixture of naphthalene and phenanthrene was analysed using GC technique. PAH from the medium was extracted using n-Hexane as a solvent. Extraction was performed thrice using $10 \mathrm{~mL}$ of $\mathrm{n}$-Hexane per cycle of extraction. Solvent phase contained the residual PAH and aqueous phase was MSM. $1 \mu \mathrm{L}$ volume of the solvent phase was used for the injection in GC instrument (Perkin Elmer Clarus 600. Column ID $-0.25 \mathrm{~mm}$ with column temperature set at maximum of $280^{\circ} \mathrm{C}$ with a holding time set at intervals of 5 minutes. Detector used - FID (Flame Ionization Detector with the detector temperature set at $250^{\circ} \mathrm{C}$ ). Analysis was performed to determine mixed $\mathrm{PAH}$ degradation at the concentration of $500 \mathrm{mg} / \mathrm{L}$.

\section{Area of study for the determination of PAH concentration in water}

The study area chosen for determining PAH concentration was Sewri, Mumbai. Sewri area is surrounded by oil refineries and petrochemical complexeswhich could lead to pollution of the water from hydrocarbons. Sewri-Mahul mud flats have been identified as an important bird area (IBA) especially for flamingos, it is also dominated by mangroves and an area where fishing is carried out. Contamination of water could pose a threat not only to birds but also it can lead to accumulation of contaminants in food chain, leading to health hazards. 5 water samples of $500 \mathrm{ml}$ volume each were collected from Sewri water-bodies $\left(19.0007^{\circ} \mathrm{N}, 72.8601^{\circ} \mathrm{E}, 19^{\circ} 0^{\prime} 13^{\prime \prime} \mathrm{N} \quad 72^{\circ} 52^{\prime} 37 " \mathrm{E}\right)$ in sampling bottles, which contained water and sediments and stored at $4^{\circ} \mathrm{C}$ till the processing. Extraction was performed thrice using n-Hexane as a solvent. Solvent phase was used as an injection sample for Gas Chromatography- Mass Spectrometry (GC-MS) analysis. 


\section{Comparison of growth in the presence of PAH and in the presence simple carbon source}

The growth of best PAH degrading isolates was checked colorimetrically in the presence of mixture of PAH (as a sole carbon source) and a simple carbon source. Glucose was used as a simple carbon source. Isolates were inoculated in $250 \mathrm{ml}$ Erlenmeyer flask containing sterile MSM medium and PAH in one flask and glucose in another flask for each isolate.The growth was estimated colorimetrically at $615 \mathrm{~nm}$.

\section{Results And Discussion}

Isolation and screening of PAH-degrading bacteria

Theenriched cultures wereused for isolation on sterile MSA plate by spread plate method. The sterileMSA plates were spray-plated with phenanthrene on the agar while naphthalene on the lid of the plate. The plates were further observed for the growth. The organisms observed to be growing on the plates were used for further studies. 30 isolates were obtained on the plates sprayed with $5 \mathrm{mg} / \mathrm{L}$ of phenanthrene and naphthalene each. Isolates were named as VP1 - VP30. Further screening was done by selecting the isolates growing on higher concentrations of phenanthrene and naphthalene. The isolated organisms which were able to grow at higher concentrations of phenanthrene and naphthalene were selected for further studies. The selected isolates were VP05, VP06, VP09, VP10, VP13, VP17, VP18 and VP20. (Table 1)

Table 1.The isolates selected for further studies based on their ability to grow in presence of phenanthrene and naphthalene at higher concentrations of $(6 \mathrm{mg} / \mathrm{L}-9 \mathrm{mg} / \mathrm{L})$. The isolates were further selected for studies on the basis of their ability to produce catechol 2, 3 dioxygenase enzyme. The '+' sign denotes production of the enzyme and '-' sign denotes no

\begin{tabular}{|c|l|l|c|c|c|}
\hline Isolate & \multicolumn{1}{|c|}{ Gram Nature } & \multicolumn{1}{|c|}{ Morphology } & $\begin{array}{c}\text { Catechol 2,3 dioxygenase } \\
\text { production }\end{array}$ & $\begin{array}{c}\text { Oxidase test } \\
\text { Cetrimide agar }\end{array}$ \\
\hline VP05 & Gram negative & Short rods & + & + & + \\
\hline VP06 & Gram negative & Short rods & + & - & + \\
\hline VP09 & Gram negative & Short rods & - & + & + \\
\hline VP10 & Gram negative & Short rods & + & + & + \\
\hline VP13 & Gram negative & Short rods & + & - & + \\
\hline VP17 & Gram positive & Rod-shaped bacilli & - & - & + \\
\hline VP18 & Gram positive & Rod-shaped bacilli & - & + & + \\
\hline VP20 & Gram negative & Short rods & + & + \\
\hline
\end{tabular}

production of the enzyme.

\section{Screening for catechol 2,3 dioxygenase production.}

Isolated colonies were checked for catechol 2, 3 dioxygenase enzyme produced during meta-cleavage pathway of PAH metabolism. The isolates able to show the production of yellowish color which further changed to red color after addition of a $0.1 \mathrm{~mL}$ of $100 \mathrm{mM}$ catechol on colonies (Figure 1A) were used for further studies (Table 1). This result suggests that the isolates produced the enzyme catechol 2, 3 dioxygenase which catalysed the conversion of catechol to 2hydroxymuconate semi aldehyde.

\section{Determining the concentration of catechol produced.}

To determine the catechol produced, a filtrate of isolates grown in medium was mixed $0.5 \mathrm{~N} \mathrm{HCl}$ and $10 \mathrm{mM}$ nitrite molybdate and the colour obtained was measured calorimetrically at $500 \mathrm{~nm}$. Three sets of tubes containing media inoculated with isolates were incubated for different time intervals of 24 hours, 48 hours and 72 hours. The colour change was observed during48-hours incubation (Figure 1B) and did not appear during 24 hours and 72-hours incubation period. This indicated that catechol was produced after 48 hours and accumulated in the medium which was further metabolized during 72-hours incubation. The results obtained were extrapolated on a standard curve for catechol. The values of the concentration of catechol produced by the isolates obtained from the graph are given in Table 2. PAH was metabolized to catechol in 48 hours. Isolate VP10 produced higher amount of catechol in 48 hours whereas other isolates produced lesser amount of catechol. This indicates that the metabolism of PAH to catechol was at a faster rate by isolate VP10 as compared to other isolates. 

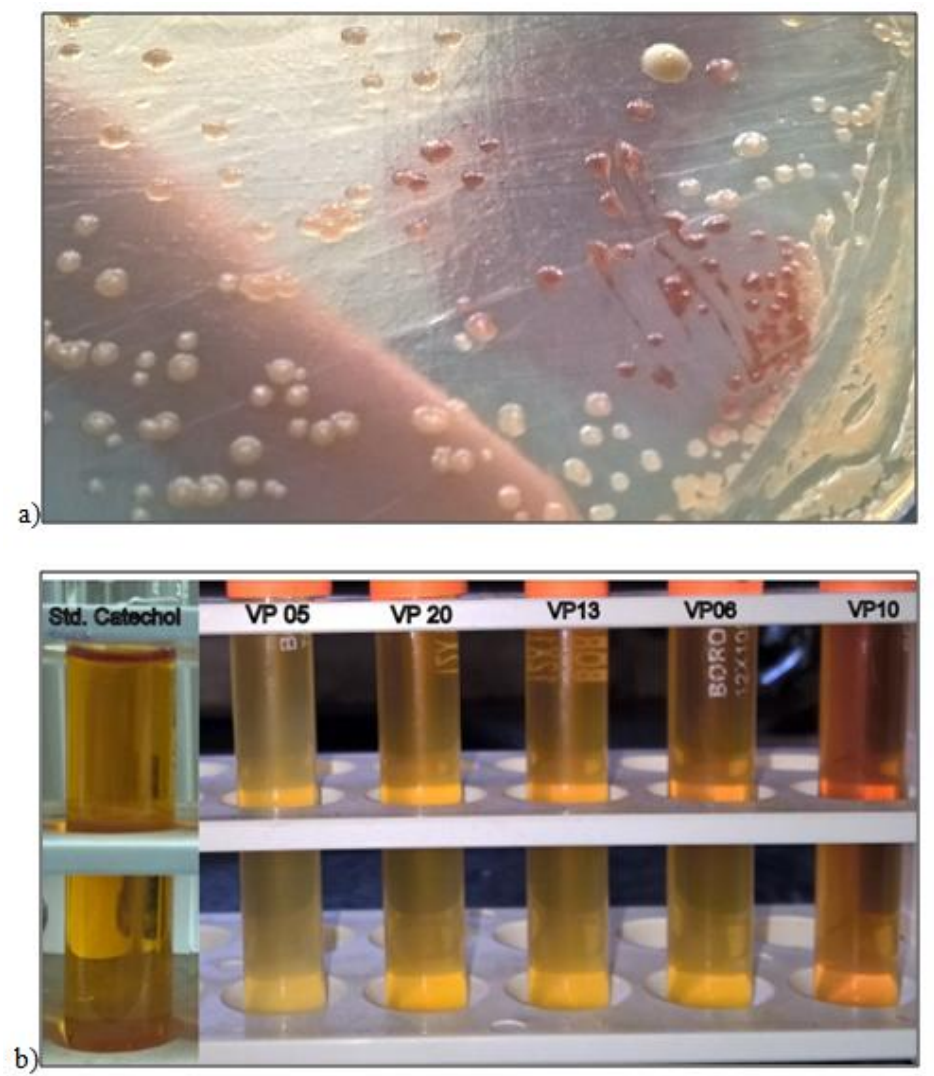

Figure 1 A. a) Bacterial colonies changed to red colour after addition of $0.1 \mathrm{~mL}$ of $100 \mathrm{mM}$ catechol on colonies. This was due to production of the enzyme catechol 2, 3 dioxygenase (isolate VP10 is shown in the figure). b) Arnow'sassay was used to determine catechol production by isolates. Catechol production by bacteria was checked after addition of nitrite molybdate to each culture suspension individually and measured colorimetrically using catechol as a standard.

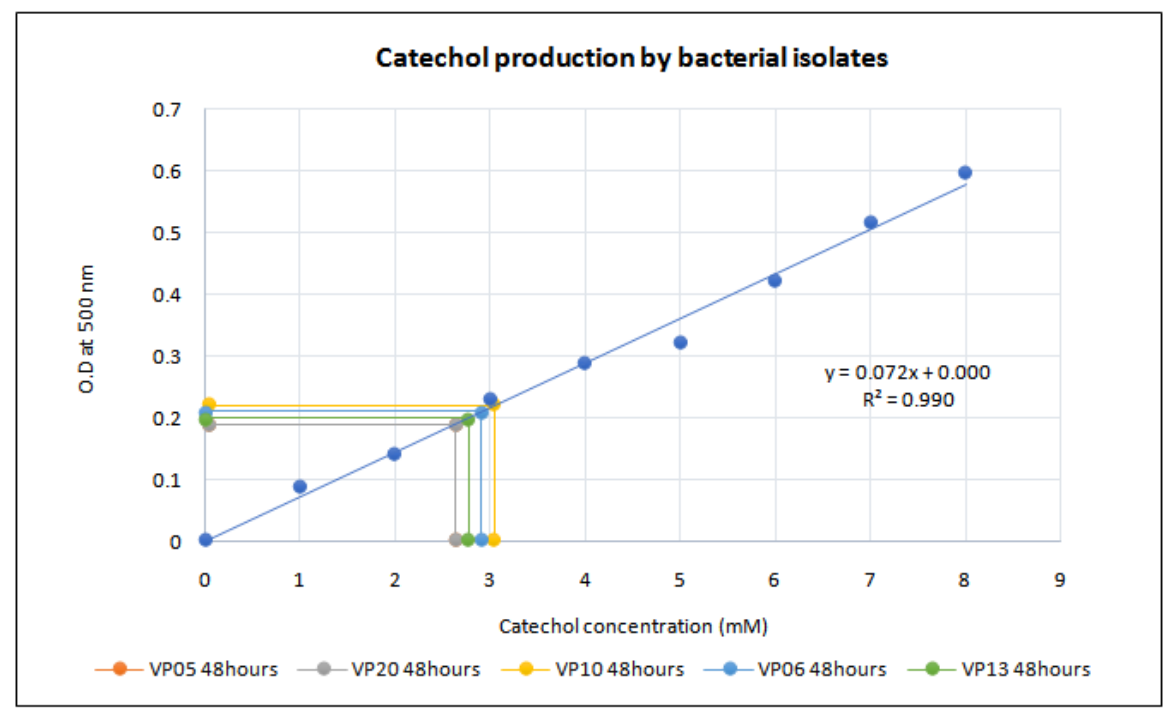

Figure 1 B.This graph represents the catechol produced by isolates after 48 hours. The unknown concentration of catechol produced by each isolate were obtained after extrapolating the O.D values against the standard graph of catechol.

Table 2. Catechol production by isolated organisms calculated using standard curve of catechol.

\begin{tabular}{|c|c|}
\hline Isolate & Catechol produced (mM/48 hours) \\
\hline VP10 & $\mathbf{3 . 0 4}$ \\
\hline VP06 & 2.90 \\
\hline VP13 & 2.76 \\
\hline VP20 & 2.64 \\
\hline VP05 & 2.64 \\
\hline
\end{tabular}


Growth response during individual and mixed PAH degradation and tolerance towards higher concentrations of PAH

To check the tolerance of isolated organisms towards higher PAH concentrations, selected isolates were grown in sterile MSM broth initially containing $10 \mathrm{mg} / \mathrm{L}$ of naphthalene and phenanthrene individually. Later, tolerance against a mixture of naphthalene and phenanthrene at a high concentration of $100 \mathrm{mg} / \mathrm{L}$ and a higher concentration of $500 \mathrm{mg} / \mathrm{L}$ was checked. A growth curve was plotted with O.D at $615 \mathrm{~nm}$ on Y axis and time in hours on axis respectively. On the basis of growth curve plotted, it was found that VP 10 had maximum growth followed by VP 06, VP13, VP20 and VP05 against a concentration of $10 \mathrm{mg} / \mathrm{L}$ for individual PAHs. During mixed PAH degradation, VP05 was not able to grow significantly. The growth curves are shown in Figure 2 to Figure 5.

VP10 was found to be highest followed by the growth of isolate VP06 and isolate VP13. The growth response indicates that, organisms were able to utilize phenanthrene and naphthalene as their sole carbon source both individually and as a mixture. As the growth proceeded, the metabolites produced during the degradation of PAH were toxic at a higher level which reduced the growth rate.

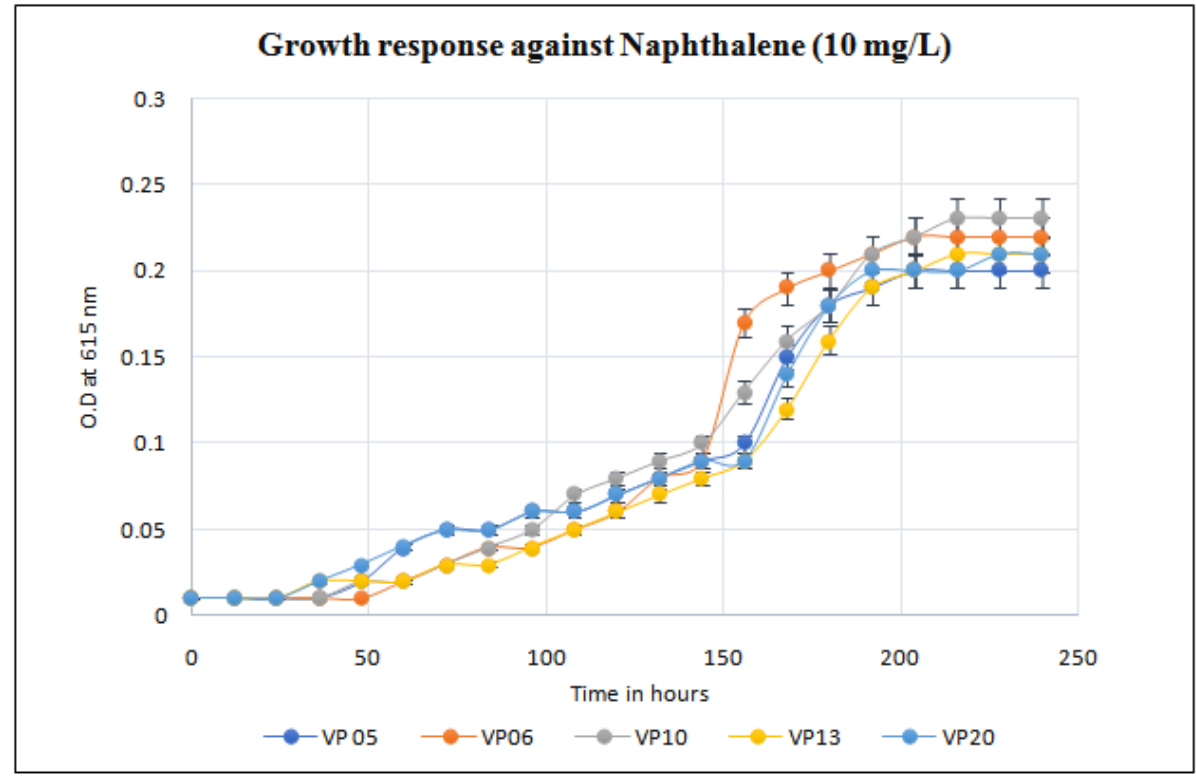

Figure 2. Growth response curve for naphthalene tolerance at a concentration of $10 \mathrm{mg} / \mathrm{L}$.Isolate VP10 showing maximum growth response.

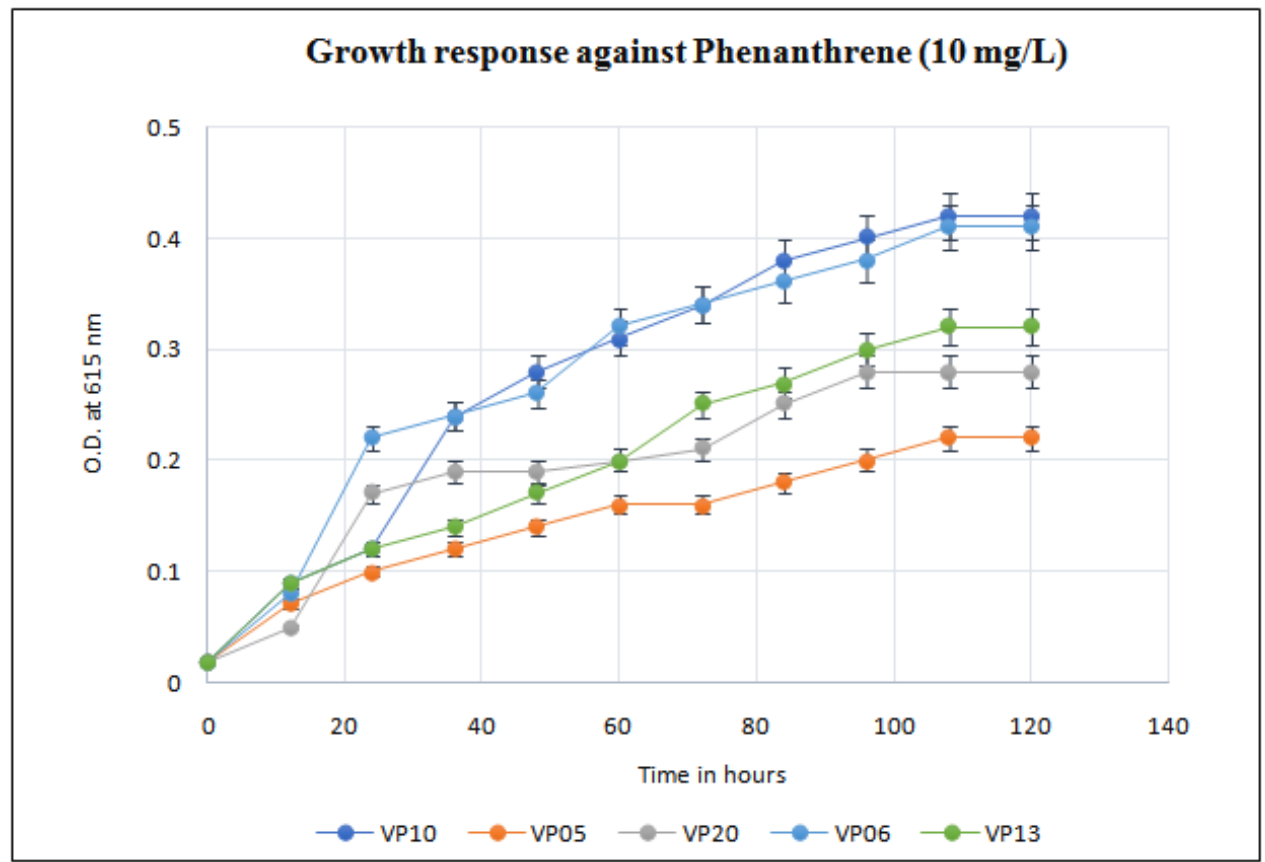

Figure 3. Growth response curve for phenanthrene tolerance at a concentration of $10 \mathrm{mg} / \mathrm{L}$. Isolate VP10 showing maximum growth response. 


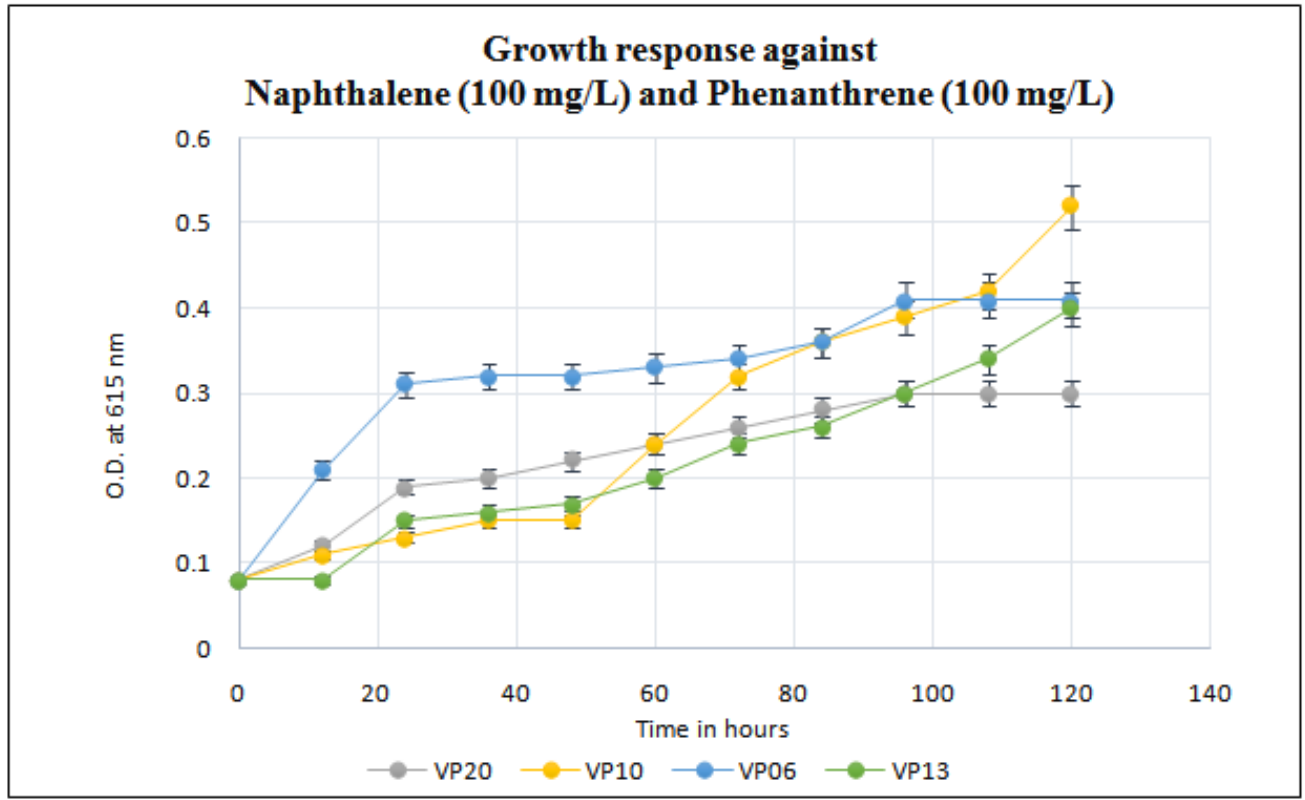

Figure 4. Growth response curve for mixture of naphthalene and phenanthrene tolerance at a concentration of $100 \mathrm{mg} / \mathrm{L}$ each.Isolate VP10 showing maximum growth response.

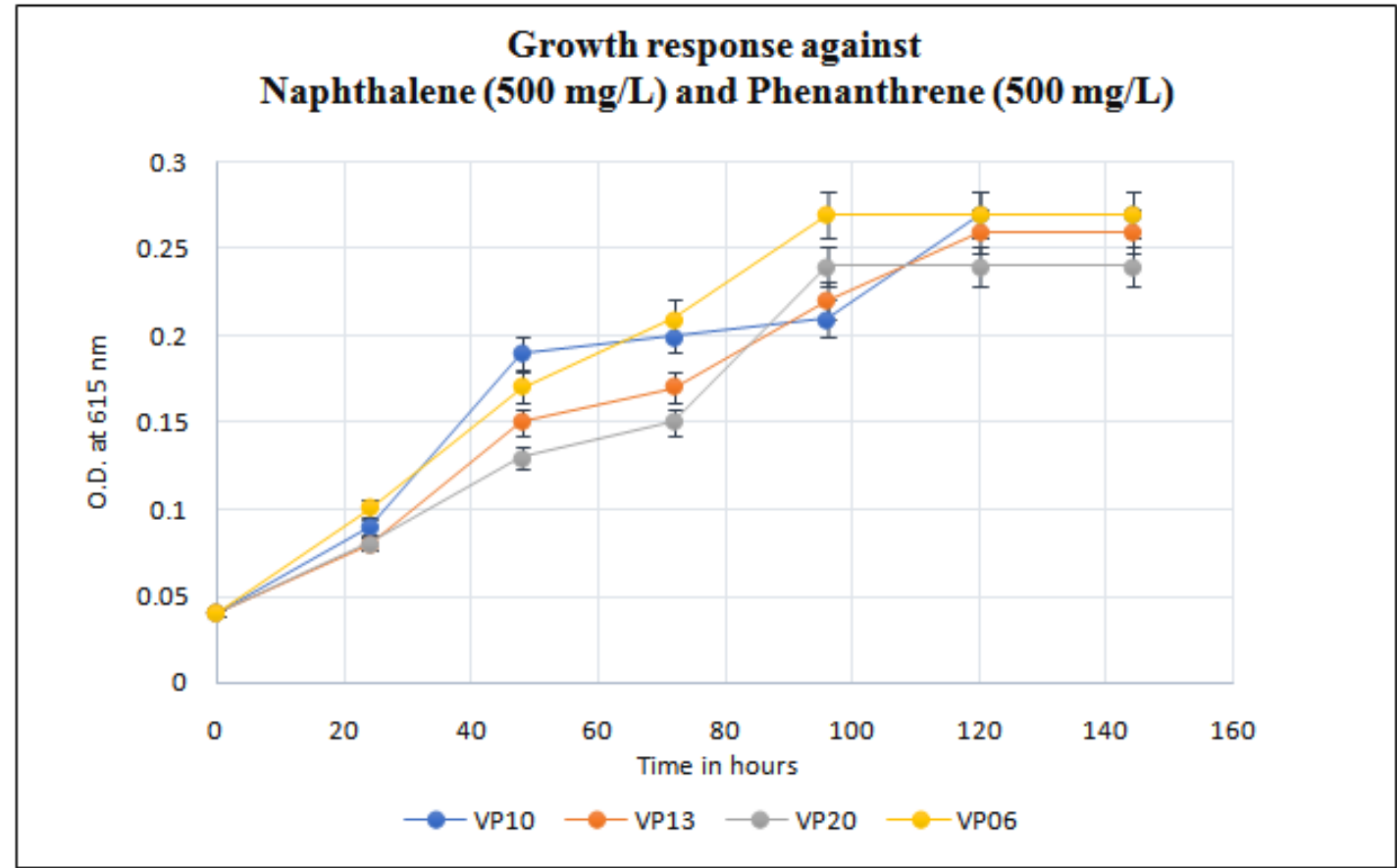

Figure 5. Growth response curve for mixture of naphthalene and phenanthrene tolerance at a concentration of $500 \mathrm{mg} / \mathrm{L}$ each.Isolate VP10 showing maximum growth response.

\section{Analysis of Mixed PAH degradation using GC}

To analyse the degradation of PAH in medium, $1 \mu \mathrm{L}$ of extracted sample (medium containing a mixture of 500 $\mathrm{mg} / \mathrm{L}$ of naphthalene and $500 \mathrm{mg} / \mathrm{L}$ of phenanthrene) was injected into the column. According to the chromatogram obtained from the analysis, the results are as follows. Isolate VP10 showed a higher rate of mixed PAH degradation with $92.3 \%$ degradation of naphthalene and 87\% degradation of phenanthrene, VP06 showed 87\% degradation of naphthalene and 32\% degradation of phenanthrene, VP13 showed $94 \%$ degradation of naphthalene while 18\% degradation of phenanthrene and VP20 showed $89 \%$ degradation of naphthalene whereas only $2 \%$ degradation of phenanthrene.

According to the results above, it can be stated that, all isolates can degrade and utilize naphthalene efficiently. Isolates VP10 and VP06 are able to degrade both naphthalene and phenanthrene in an efficient way. Though VP 10 showed better growth in presence of naphthalene as a sole carbon source but during mixed PAH degradation, VP13 showed a better degradation of naphthalene than other isolates. The chromatograms of analysis are showed in Figure 6 to Figure 9. 


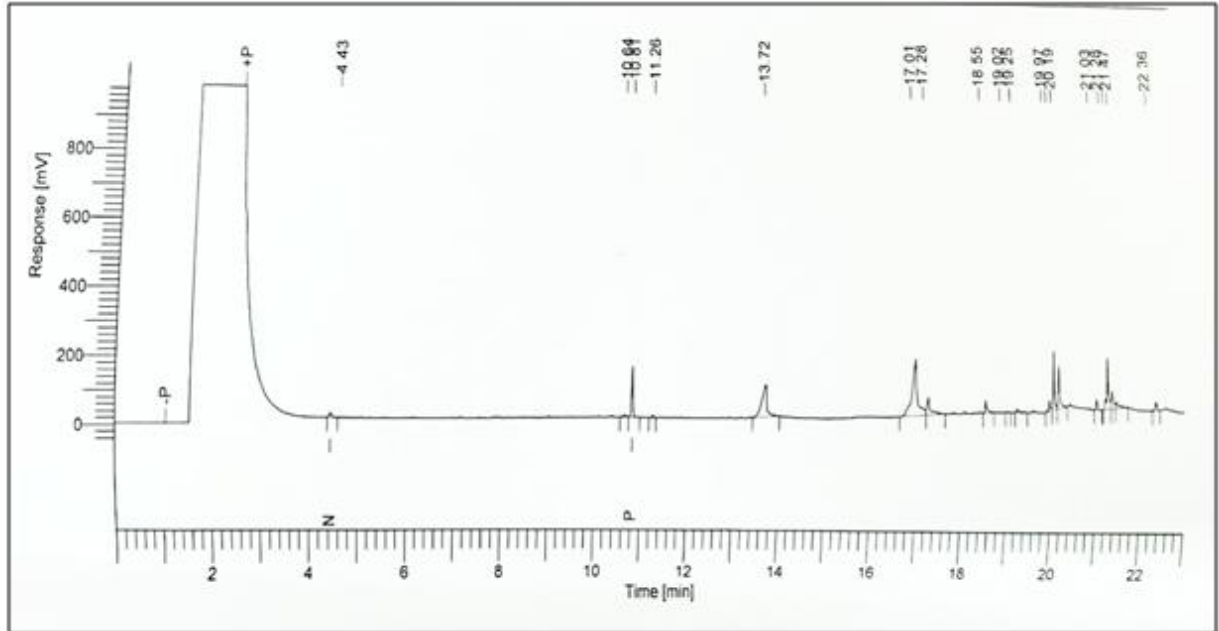

Figure 6.The chromatogram showing mixed PAH degradation by isolate VP 10. Naphthalene was degraded to92.3\% and phenanthrene was degraded to $87 \%$. 'N' denotes naphthalene and 'P' denotes phenanthrene.

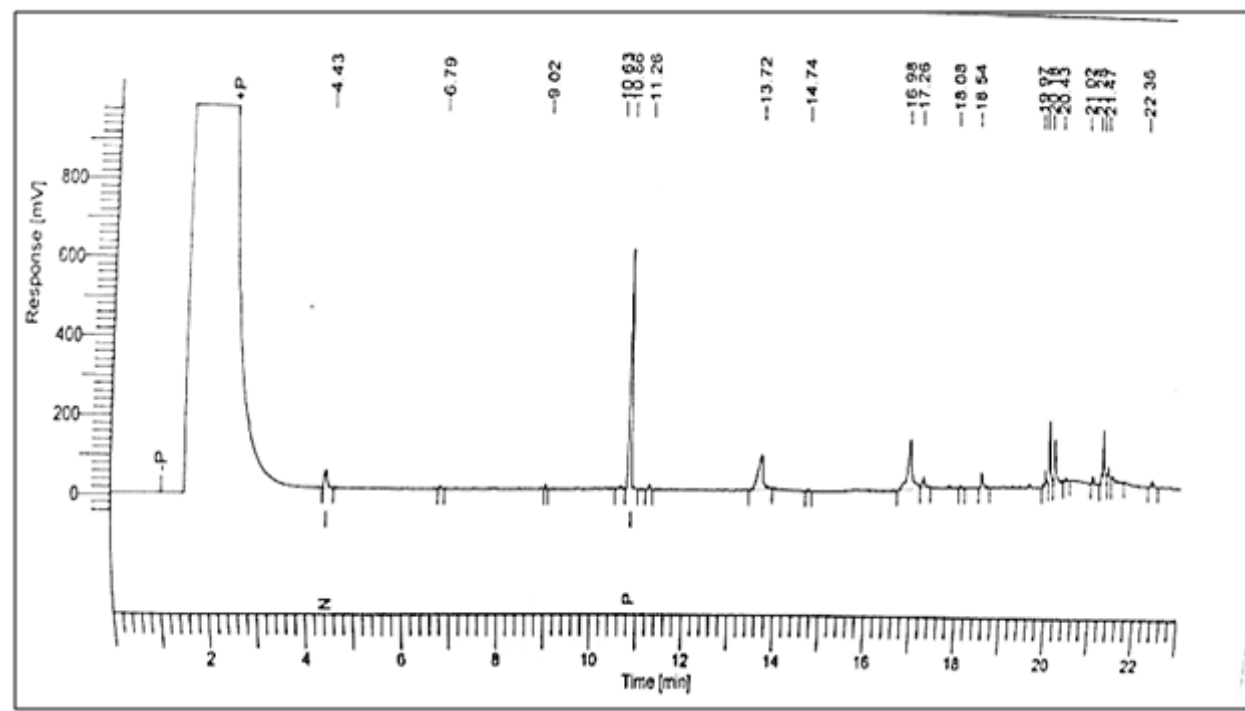

Figure 7.The chromatogram showing mixed PAH degradation by isolate VP 06 . Naphthalene was degraded to $87 \%$ and phenanthrene was degraded to $32 \%$. ' $\mathrm{N}$ ' denotes naphthalene and ' $\mathrm{P}$ ' denotes phenanthrene.

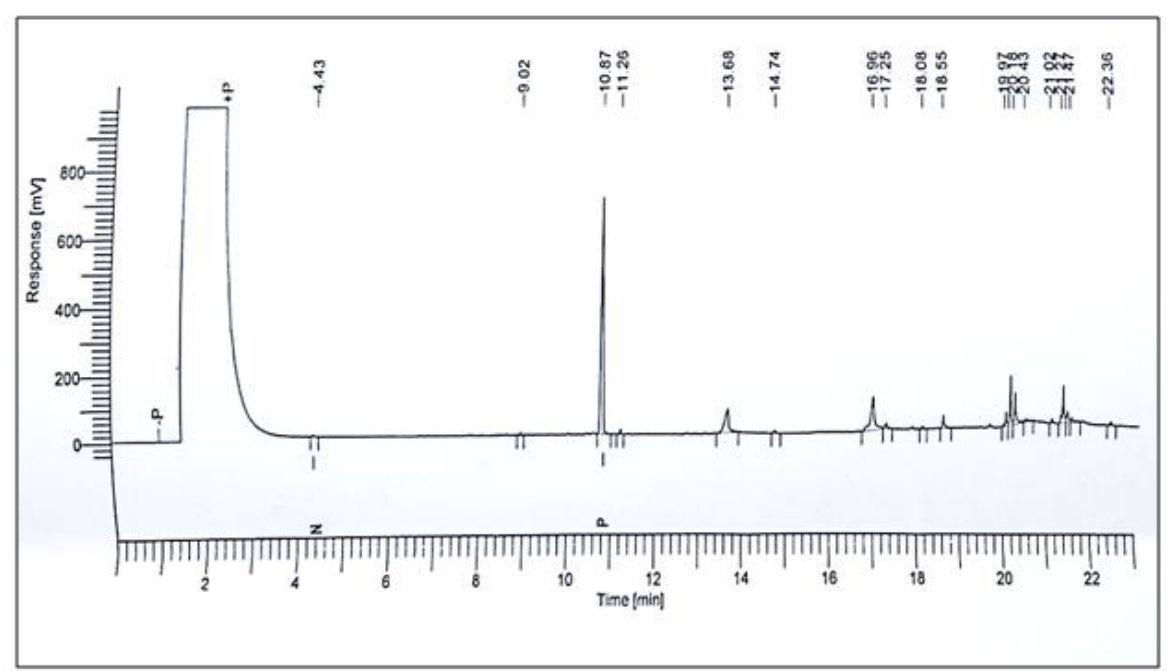

Figure 8. The chromatogram showing mixed PAH degradation by isolate VP 13. Naphthalene was degraded to94\%, phenanthrenewas degraded to $18 \%$. 'N' denotes naphthalene and 'P' denotes phenanthrene (above $\mathrm{X}$ axis). 


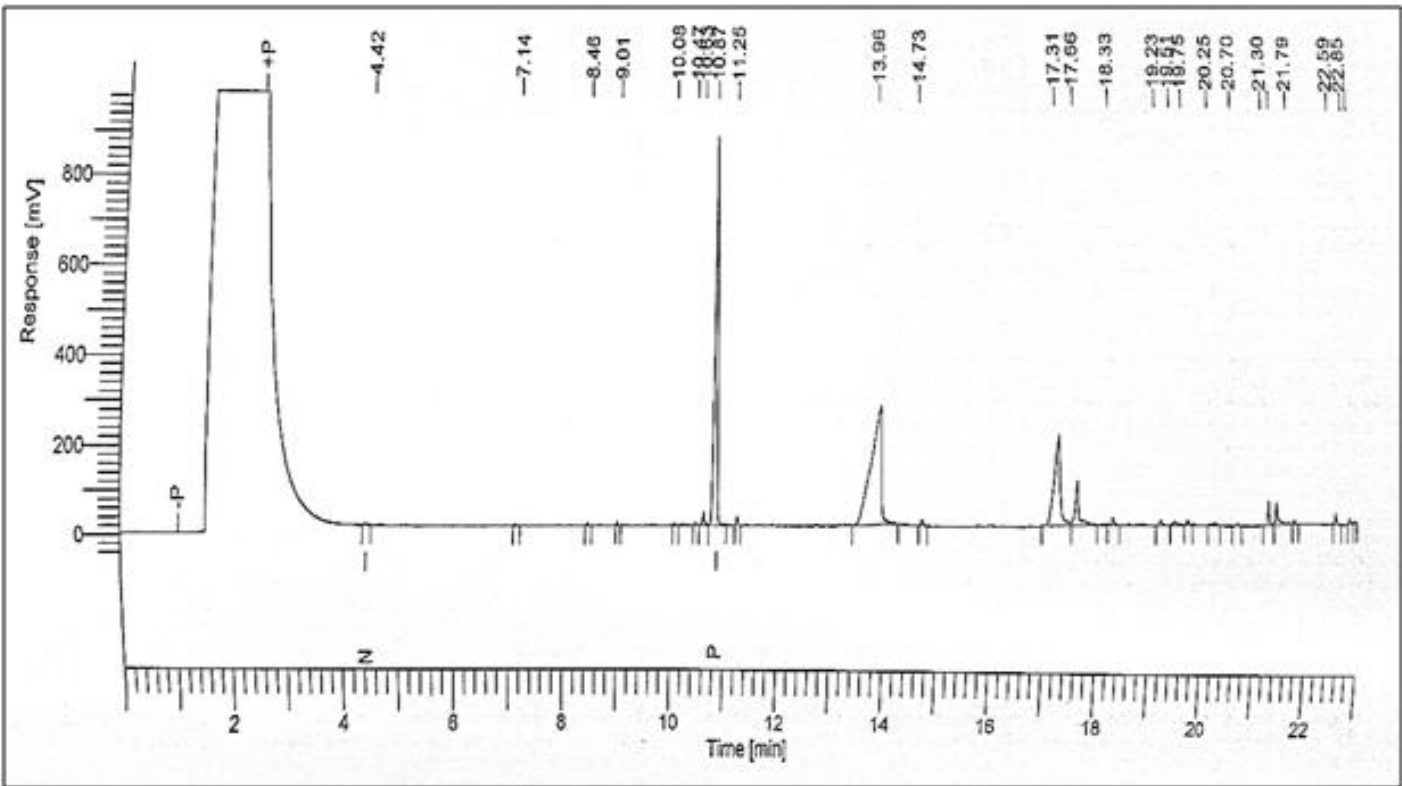

Figure 9. The chromatogram showing mixed PAH degradation by isolate VP 20. Naphthalene was degraded to $89 \%$ andphenanthrenewas degraded to $2 \%$. ' $\mathrm{N}$ ' denotes naphthalene and ' $\mathrm{P}$ ' denotes phenanthrene

\section{Area of study for the determination of PAH concentration in water}

GC-MS analysis of the water samples collected from Sewri, Mumbai area revealed that high concentration of Naphthalene and an unknown high-molecular weight hydrocarbon is present (Figure 10 - Figure 12).The $\Sigma \mathrm{PAH}$ in water samples was found to be in the range of $1.47 \times 10^{2}-6.52 \times 10^{2} \mathrm{mg} / \mathrm{L}$ (Table 3) which is much more than the permissible limits set by WHO for PAH in water which are $5 \times 10^{-5}$ for surface and coastal waters and $1 \times 10^{-6}-1.1 \times 10^{-2}$ for drinking water[19](Table 3).

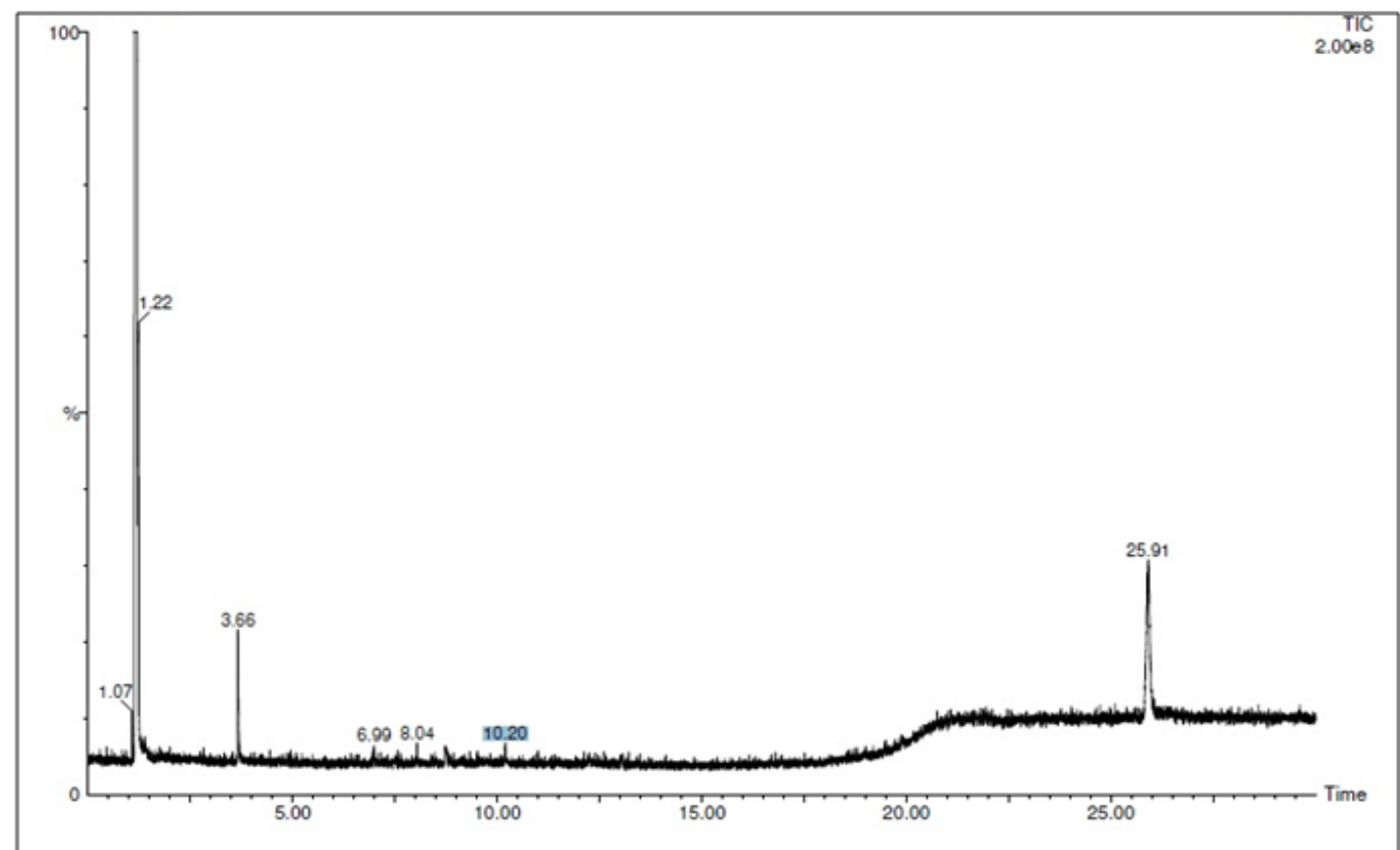

Figure 10. The chromatogram showing presence of Naphthalene (3.66mins) and a high molecular weight hydrocarbon (25.91 minutes) in the water sample.

Table 3. Concentration of PAHs determined using GC-MS analysis of the water samples and its comparison with the permissible limits set by WHO for PAH in water bodies.

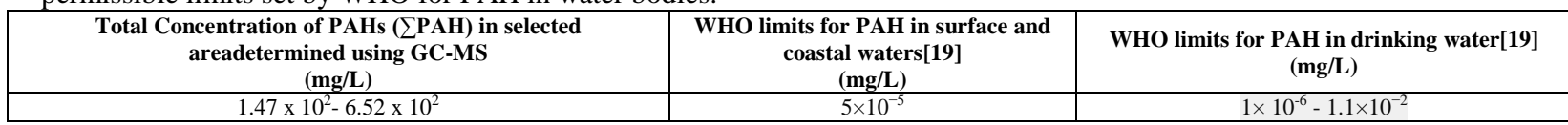




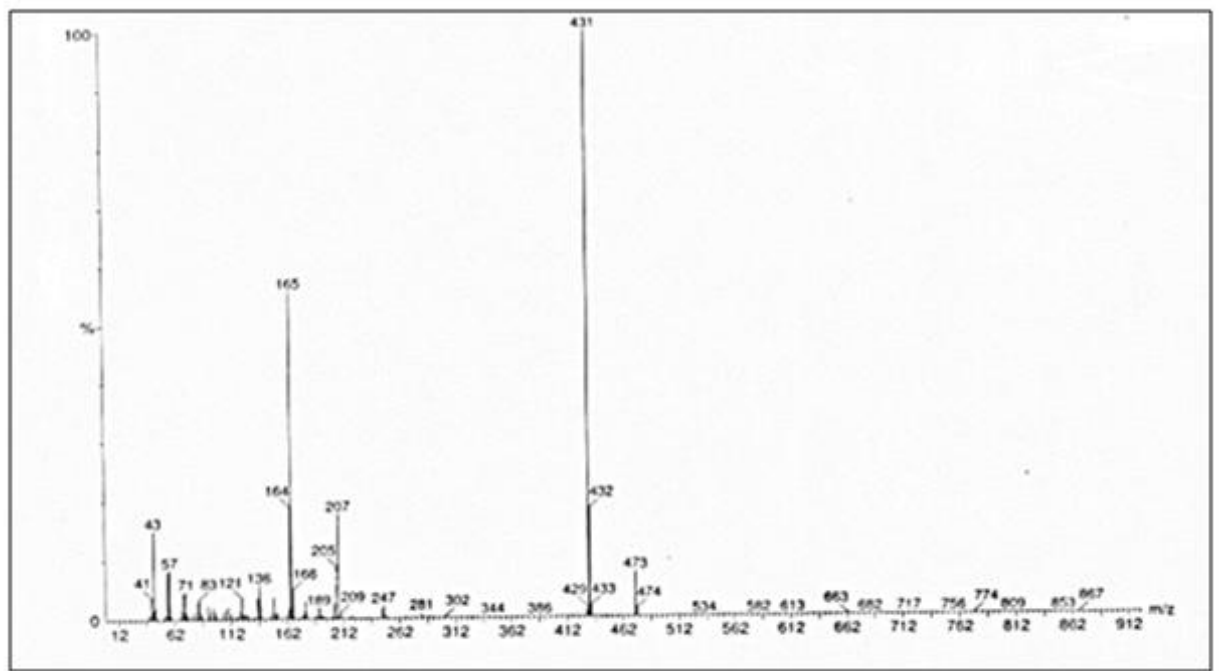

Figure 11. The GC-MS profile of the high molecular weight hydrocarbon.

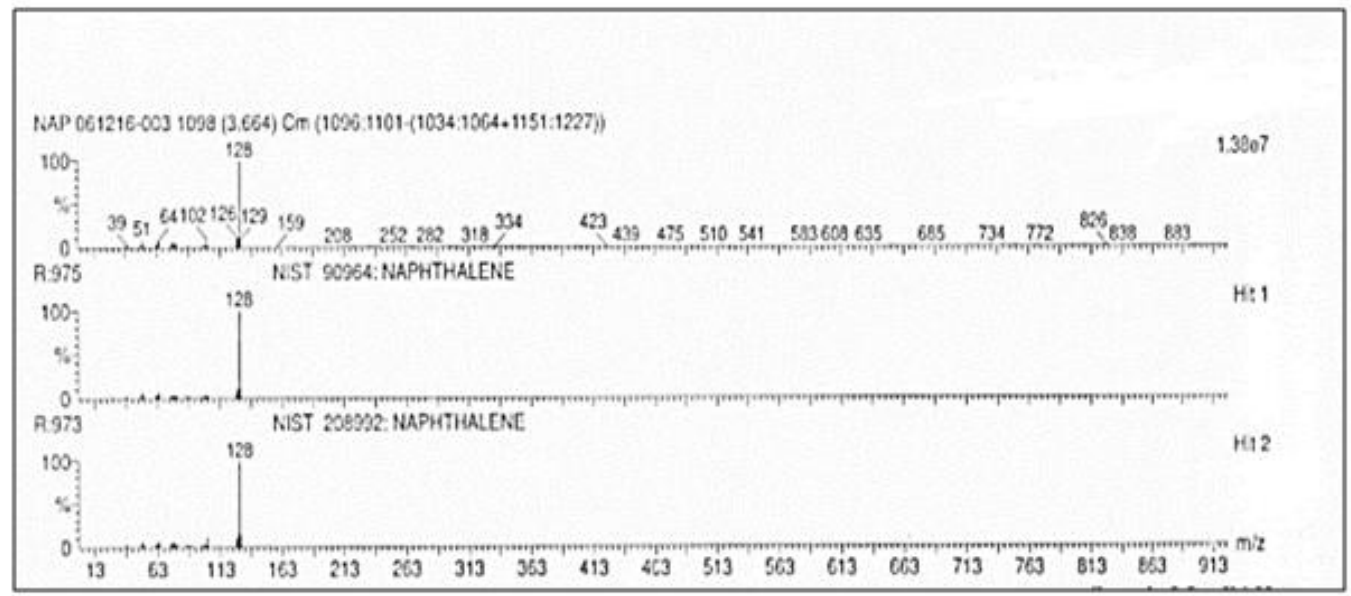

Figure 12. The GC-MS profile of Naphthalene.

\section{Comparison of growth in the presence of PAH and in the presence simple carbon source}

The isolates which showed good degradation of PAH were further used to study the growth in presence of PAH and glucose as sole carbon source. VP06 and VP10 were used for further studies. From the growth curve performed, it was observed that the isolates were able to grow in presence of mixture of PAH almost as efficiently as they were able to grow in the presence of glucose. Hence these organisms can efficiently use PAHs as a carbon source if a simpler carbon source like glucose is not available. The growth response curve is showed in Figure 13.

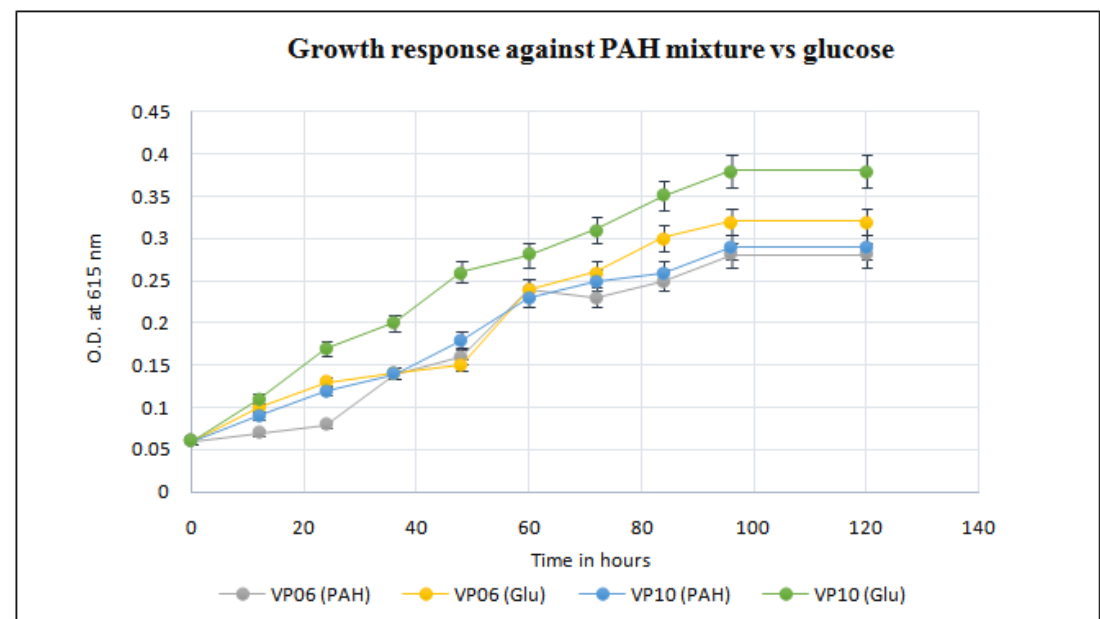

Figure 13. Growth response curve against a mixture of PAH and against glucose as a sole carbon source. 


\section{Conclusion}

The area of study was found to be highly contaminated with hydrocarbon which surpassed the permissible limits set by WHO. PAH degrading microorganisms were isolated from sites contaminated with hydrocarbon waste. The isolates obtained were able to metabolize phenanthrene and naphthalene as sole source of carbon. From the isolates obtained isolates VP10, VP06 and VP13 were found to be not only tolerating and metabolizing higher concentration of individual PAH but also a mixtureof PAHs as compared to other isolates. These isolates were found to be degrading naphthalene and phenanthrene via meta-cleavage [3,12]. Further studies include identification of the selected isolates and identifying the metabolites produced during metabolism of PAH. The isolates were able to degrade the PAH at a concentration higher than that was found in the water samples collected from area of study. Hence these isolates can be used for the bioremediation of the contaminated water.

\section{Acknowledgement}

The authors are grateful to the Head of the department, teaching staff, non-teaching staff, Vice Principal and Principal of Vikas College of Arts, Science and Commerce, Vikhroli, Mumbai and SIES College of Arts, Science and Commerce, Sion, Mumbai for providing the facilities for the bench work.The authors want to thank SIES Institute of Chromatography and Spectroscopy for providing the facility for Gas Chromatography and Mass Spectroscopy.

\section{References}

[1]. Arnow. L. E. 1937, Colorimetric determination of the components of 3, 4-dihydroxyphenylalanine tyrosine mixtures. Journal of Biological Chemistry. 118, 531-537.

[2]. BroderickJ.B.1999. Catechol dioxygenases. Essays in Biochemistry. 34. 173-189.

[3]. Dhananjayan V. and Muralidharan S., 2012. Polycyclic Aromatic Hydrocarbons in Various Species of Fishes from Mumbai Harbour, India and Their Dietary Intake Concentration to Human International Journal of Oceanography.1-6.

[4]. Franklin F.C., Bagdasarian M. and Timmis K.N. 1981. Molecular and functional analysis of the TOL plasmid pWWO from Pseudomonas putida and cloning of genes for the entire regulated aromatic ring Meta cleavage pathway. Proceedings of the National Academy of Sciences.78, 7458-7462.

[5]. Ghosal D., Chakraborty J., Khara P. and Tapan K. D. 2010. Degradationofphenanthreneviameta -cleavageof2-hydroxy1naphthoicacidby Ochrobactrumsp.strainPWTJD. FEMS Microbiology Letter. 313, 103-110.

[6]. Hussein I. and Mansour M., 2016. A review on polycyclic aromatic hydrocarbons: Source, environmental impact, effect on human health and remediation.25(1), 107-123.

[7]. Moody J. D., Freeman J. P., Doerge D. R. and Cerniglia C. E. 2001. Degradation of Phenanthrene and Anthracene by Cell Suspensions of Mycobacterium sp. Strain PYR-1. Applied and environmental microbiology.67, 1476-1483.

[8]. Kimtrele M. W., William E. M., Justin S., Baraka S. W. and Bianca L. G. 2012. Production of Protocatechuic Acid in Bacillus Thuringiensis ATCC33679. International journal of Molecular Science. 13, 3765-3772.

[9]. Kiyohara H., Nagao K. and Yana K.1982. Rapid Screen for Bacteria Degrading Water-Insoluble, Solid Hydrocarbons on Agar Plates. Applied and Environmental Microbiology. 43, 454-457.

[10]. Kumar M., Leon V., Materano A.D.S., Ilzins O.A., Ivan G.C. and Fuenmayor S.L. 2006. Polycyclic Aromatic Hydrocarbon Degradation by Biosurfactant-Producing Pseudomonas sp.IR1.Z. Naturforsch. 61, 203- 212.

[11]. MPCB <http://mpcb.gov.in/ereports/ereportsdetail.php>.

[12]. Pawar A., UgaleS., More M., Kokani N. and Khandelwal S. 2013. Biological Degradation of Naphthalene: A New Era. 4 (7), $1-5$.

[13]. Roy M., Khara P.and Dutta T. K.2012. Meta-Cleavage of hydroxyl naphthoic acids in the degradation of phenanthrene by Sphingobium sp. strain PNB. Microbiology, 158, 685-695.

[14]. Sądej W. and Namiotko A. 2010. Content of Polycyclic Aromatic Hydrocarbons in Soil Fertilized with Composted Municipal Waste. Polish Journal of Environmental Studies. 19, 999-1005.

[15]. Sopena F., Laiz L., Morillo E., Antonia Sanchez-Trujillo M.., Villaverde J., Jurado V. and Saiz-Jimenez C. 2013. Phenanthrene biodegradation by Pseudomonas xanthomarina isolated from an aged contaminated soil. CLEAN - Soil, Air, and Water. 42, 785790 .

[16]. Srujana K and Khan A.B. 2012. Isolation and Characterisation of Polycyclic Aromatic Hydrocarbon Degrading Soil Microbes from Automobile Workshop Sediments. Journal of Environmental Science and Technology. 5, 74-83.

[17]. Tao X.Q., Lu G.N., Dang Z., Yang C. and Yi X.Y. 2007. A phenanthrene-degrading strain Sphingomonas sp. GY2B isolated from contaminated soils. Process Biochemistry. 42. 401-408.

[18]. Tao X.Q., Liu J.P., Lu G.N., Guo X., Jiang H.P. and Sun G.Q. 2010. Biodegradation of phenanthrene in artificial seawater by using free and immobilized strain of Sphingomonas sp. GY2B. African Journal of Biotechnology. 9, 2654-2660.

[19]. WHO <http://www.who.int/water_sanitation_health/dwq/chemicals/polyaromahydrocarbons.pdf $>$

[20]. Ying Z., Jiashi W., Tao J., Weifeng G., Yushu M. and Dongzhi W. 2007. Characterisation of a thermostable catechol-2, 3dioxygenase from phenanthrene-degrading Pseudomonas sp. strain ZJF08. Annals of Microbiology. 57, 503-508.

[21]. Zhu X., Ni X., Waigi M., Liu J., Sun K., and Gao Y.2016. Biodegradation of Mixed PAHs by PAH-Degrading Endophytic Bacteria. Int J Environ Res Public Health. 13 (8), 1-13. 